\title{
Política de atenção integral aos usuários de álcool e outras drogas: retrocessos nas concepções, desenho e financiamento
}

Comprehensive care policy for users of alcohol and other drugs: regressions in conception, design, and financing

\author{
Juliana Desiderio Lobo Prudencio* \\ Mônica de Castro Maia Senna**
}

\begin{abstract}
Resumo - A constituição da política de saúde mental, álcool e outras drogas tem sido tensionada por duas lógicas orientadoras distintas: a repressão e a estratégia de redução de danos. O presente artigo busca analisar a construção da política de atenção aos usuários de drogas e mostrar os retrocessos infligidos a essa política, em especial a partir do ano de 2017. A partir da revisão de literatura e levantamento documental, examina a trajetória, contextos, atores envolvidos e conteúdo da política, analisando o perfil dos gastos dos ministérios da Saúde e da Justiça nesse campo como expressão das tensões e disputas entre lógicas distintas e até mesmo antagônicas. Os resultados mostram que medidas adotadas pelo governo federal têm priorizado as comunidades terapêuticas, esvaziado o caráter comunitário e territorial dos Caps e priorizado o financiamento de ações antidrogas, em nítido desmantelamento da política em seu formato articulado à reforma psiquiátrica antimanicomial e antiproibicionista brasileira.

Palavras-chave: política de saúde mental; política sobre drogas; orçamento público.
\end{abstract}

\begin{abstract}
The creation of policies for mental health, alcohol, and other drugs has been strained by two distinct guiding principles: repression and harm reduction. This article aims to analyze the creation of care policy for drug users in order to highlight the regressions inflicted on this policy, especially from 2017 onwards. Based on literature review and document survey, this paper examines the legacy, contexts, players, and contents of that policy. It analyzes the spending profile of the Ministry of Health and Ministry of Justice in this field as an expression of tensions and disputes between different and even antagonistic ideas. The results show that measures adopted by the fe-
\end{abstract}

\footnotetext{
* Doutora em Política Social pela Universidade Federal Fluminense. Professora Adjunta do Departamento de Serviço Social de Campos do Goytacazes da Universidade Federal Fluminense. E-mail: julianalobo@id.uff.br ORCID: https:/ /orcid.org/0000-0003-3068-0097.

** Doutora em Ciências - Saúde Pública. Professora Titular do Programa de Estudos Pós-graduados em Política Social e da Escola de Serviço Social da Universidade Federal Fluminense. Pesquisadora CNPq. E-mail: monica_senna @id.uff.br. ORCID:https://orcid.org/0000-0003-2161-7133.
} 
deral government have prioritized Therapeutic Communities, deemphasized the community and territorial character of CAPS, and given preference in financing for anti-drug actions. Those actions were taken by the federal government and result in dismantling the policy as it was designed by the Brazilian Anti-Asylum and Antiprohi-bitionist Psychiatric Reform.

Keywords: mental health policy; drug policy; public budget.

\section{Introdução}

As primeiras incursões realizadas pelo setor de saúde brasileiro no campo do álcool e outras drogas remontam ao século XIX e foram, por longo tempo, sustentadas por concepções eugênicas e higienistas. Sob o monopólio do saber médico, estabeleceu-se um estatuto médico-jurídico no trato público da questão que conferiu legitimidade às ações repressivas, proibicionistas, moralizantes e de controle sobre o uso de drogas e sobre seus usuários (LIMA, 2009).

É somente nos anos 1980 que a preocupação da área da saúde com a questão do álcool e outras drogas ganha novos contornos, impulsionada sobretudo pela emergência da epidemia da Aids (Síndrome da Imunodeficiência Adquirida). A incorporação ao campo da saúde pública e sua associação à adoção da estratégia de redução de danos (RD) foram provocadoras de importantes avanços na forma de conceber e intervir na questão das drogas, apontando para outras possibilidades, distintas do proibicionismo e da abstinência total.

Importante avanço no trato da questão dos usos do álcool e de outras drogas foi a aproximação da temática ao campo da saúde mental, impulsionada pela publicação da Lei da Reforma Psiquiátrica Brasileira (Lei Federal no 10.216, de 2001 - BRASIL, 2001). Entre as inovações trazidas pela lei estão o reforço dos serviços extra-hospitalares de base comunitária e territorial, capazes de ser uma referência institucional permanente de cuidados (PITTA, 2011), e o reconhecimento das pessoas em sofrimento psíquico como sujeitos de direitos.

Ainda que sem promover uma ruptura radical com o modelo manicomial, a lei contribuiu para ressignificar a questão do álcool e outras drogas, abrindo possibilidades para o reconhecimento dos usuários dessas substâncias como sujeitos e determinando que o cuidado deve ocorrer no território, de modo a respeitar a história, cultura e vínculos sociais. A partir daí, várias medidas normativas, entre 2001 e 2017, contribuíram para ampliar a perspectiva da atenção à saúde dos usuários de álcool e outras drogas, se contrastada com a lógica puramente repressiva anterior.

Tensões e disputas entre concepções e práticas em torno da questão marcaram esse processo. Mas é a partir de 2017 que há um aprofunda- 


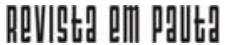

\} POLÍTICA DE ATENCCÃO - PRUDENCIO, J. D. L.; SENNA, M. C. M.

DOI: $10.12957 /$ REP.2022.63449

mento da onda de retrocessos para a política de saúde mental, álcool e outras drogas, em especial com a implantação da nova política de saúde mental e da nova Raps, o que provocou alterações importantes na assistência e deu espaço às comunidades terapêuticas como serviço primário de cuidado.

O presente artigo examina os rumos assumidos pela política de saúde no campo do álcool e outras drogas no Brasil, identificando tensões, avanços e retrocessos ao longo de sua trajetória. O estudo toma como ponto de partida a implantação da política de atenção integral aos usuários de álcool e outras drogas (Paiuad), em 2003, quando o tema entra, de fato, na agenda da saúde pública brasileira. Acompanha essa trajetória até junho de 2021, no contexto da pandemia por Covid-19.

O estudo se pautou em pesquisa bibliográfica e documental, com consulta a livros, artigos em periódicos, relatórios e teses sobre a temática, além de páginas oficiais dos ministérios da Saúde e da Cidadania. O recorte temporal da consulta foi de 2001 até junho de 2021. O plano de análise considerou o contexto de produção das políticas, os atores e interesses envolvidos e o conteúdo da política. Analisou ainda o padrão de gastos dos ministérios da Saúde e da Justiça com as intervenções voltadas à atenção aos usuários de drogas e ao combate ao tráfico de drogas entre 2005 e 2019, a partir do estudo realizado pelo Ipea (2021) nos planos plurianuais do período, contrastando as lógicas proibicionistas e de redução de danos que têm majoritariamente orientado as intervenções nesse campo.

\section{A conformação do tema álcool e outras drogas na agenda da saúde pública brasileira}

A inclusão do tema drogas no âmbito do Sistema Único de Saúde (SUS) foi possibilitada com a implantação, em 2003, da Paiuad (BRASIL, 2003). Tendo como principais referências a estratégia de redução de danos e o tratamento extra-hospitalar de base comunitária referido no território, o Paiuad trouxe uma noção ampliada em relação ao enfoque da RD, incorporando suas dimensões sociais e de saúde a partir da perspectiva de minimização das consequências adversas do uso do álcool e outras drogas, sem necessariamente reduzir o seu consumo.

Não se pode esquecer aqui a contribuição dos movimentos sociais e dos trabalhadores da saúde mental ao longo desse processo, merecendo sublinhar as deliberações da III Conferência Nacional de Saúde Mental, realizada em 2001, cujo relatório final incorpora, pela primeira vez no campo, a temática da droga como pauta do eixo referente à reorientação do modelo assistencial em saúde mental. Coe e Duarte (2017) sublinham a potência desses movimentos sociais na medida em que buscaram articular a ocupação tática de espaços estratégicos na gestão governamental com a 
manutenção de sua identidade como movimento social, por meio das associações de usuários e familiares e do movimento antimanicomial, possibilitando a ampliação da agenda política do campo da saúde mental para outras questões, dentre elas os usos do álcool e outras drogas.

No mesmo período são criados ou redefinidos diversos serviços, tais como o Caps-AD, o consultório na rua e as unidades de acolhimento. Seguindo essa tendência, em 2011 foi constituída, por meio da Portaria Ministerial no 3.088/2011 (BRASIL, 2011), a Rede de Atenção Psicossocial (Raps), com o objetivo de ampliar e promover o acesso à atenção psicossocial das pessoas em sofrimento psíquico, transtorno mental e/ou uso de crack, álcool e outras drogas, orientando-se por diretrizes ancoradas no respeito aos direitos humanos, no combate ao estigma e ao preconceito, na garantia da qualidade dos serviços prestados, na construção da integralidade e da intersetorialidade e na participação dos usuários, familiares e comunidade na definição do projeto terapêutico.

A ampliação do acesso ao cuidado em saúde mental e a redução do número de leitos em hospitais psiquiátricos, associadas à expansão e regionalização da rede de serviços substitutivos, têm sido destacadas como importantes conquistas pela literatura voltada ao estudo sobre o tema, dentre eles os trabalhos de Macedo et al. (2017) e Lima e Guimarães (2019). Não obstante os avanços representados pela implantação da Raps, sobretudo no que diz respeito ao esforço de constituição de uma rede integrada de serviços de saúde, é preciso considerar alguns tensionamentos e limites em sua implementação.

A definição da atenção básica em saúde como ordenadora do cuidado tem sido frequentemente conflitada com a centralidade assumida pelos Caps na política de saúde mental a partir dos anos 2000. Amarante (2003) já alertava para o caráter contraditório dessa centralização dos Caps vis-à-vis a própria ideia de rede substitutiva e comunitária, um dos pontos chave do movimento em prol da reforma psiquiátrica brasileira. O autor chegou a cunhar a expressão "capsização" para se referir a essa centralidade.

Sem desconsiderar a relevância histórica dos Caps como parte do avanço das políticas de saúde mental no Brasil e do reconhecimento dos direitos das pessoas em sofrimento psíquico e usuários de drogas, o que se quer chamar atenção aqui é para o risco de perpetuação de uma lógica de cuidado especializado e de urgência em detrimento de perspectivas de atenção contínua e de base comunitária e territorial (COSTA; RONZANI; COLUGNATI, 2018). Na mesma direção, Coe e Duarte (2017) advertem que, ao definir os Caps como dispositivo de atenção psicossocial especializada e não incorporar os ambulatórios de saúde mental no âmbito da rede, a Raps tende a induzir a um processo de "ambulatorização" dos Caps, limitando-os a atendimentos especializados próprios da média complexidade. 


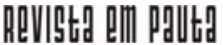

\} POLÍTICA DE ATENCCÃO - PRUDENCIO, J. D. L.; SENNA, M. C. M.

DOI: $10.12957 /$ REP.2022.63449

Os autores sublinham ainda fragilidades relacionadas à insuficiência do número de Caps-AD no território brasileiro e sua desigual distribuição pelas regiões do país, indicativos da baixa cobertura desses dispositivos, mesmo com a expansão observada na última década. Esse quadro, aliado ainda à precarização dos vínculos profissionais e à baixa densidade de articulação de ações intersetoriais que ultrapassem o próprio setor saúde, acaba por limitar o potencial da Raps, levando ao risco de reduzi-la a um mero mecanismo de regulação e organização dos fluxos assistenciais no interior do SUS, engessado por seus parâmetros normativos.

\section{Tensões e retrocessos na atenção aos usuários de álcool e outras drogas}

Os avanços conquistados na atenção à saúde aos usuários de álcool e outras drogas têm sido tensionados, ao longo de toda sua trajetória, pela persistência da lógica proibicionista, expressa nas políticas públicas de guerra às drogas, apontando para as disputas, conflitos e contradições nesse processo. Na mesma data em que era realizada a III Conferência Nacional de Saúde Mental, em 2001, ocorria também o II Fórum Antidrogas, convocado pelo Conselho Nacional Antidrogas (Conad) e pela Secretaria Nacional Antidrogas (Senad), ambos instituídos em 1998 e integrados, em 2000, ao então recém-criado Sistema Nacional Antidroga (Sisnad). Esse fórum homologa a política nacional antidrogas (PNAD).

A PNAD de 2001 até faz menção à RD, mas a limita a uma estratégia de prevenção de doenças infectocontagiosas. O enfoque principal dessa política reafirma o proibicionismo às drogas e a abstinência total, apontando em direção ao ideário de uma sociedade livre dessas substâncias e reforçando a declaração de "guerra às drogas". Essa tendência é ainda acentuada pelo fato de que o Sisnad, sistema responsável pela operacionalização da política, vinculava-se diretamente ao Gabinete de Segurança Institucional (GSI) da presidência da República.

Em 2005, a PNAD foi substituída pela política nacional sobre drogas, vinculada ao Ministério da Justiça e Segurança Pública. Embora ainda mantendo a perspectiva de redução da oferta nos moldes da PNAD que a antecedeu, essa nova política, diferente da anterior, incorpora a RD como estratégia de cuidado e prevenção de riscos e danos sociais e à saúde. No entanto, conforme assinala Prudencio (2019), essa incorporação não foi suficiente para ultrapassar a determinação da abstinência total como estratégia central na redução dos problemas sociais, econômicos e de saúde decorrentes dos usos do álcool e outras drogas. O que se quer ressaltar com essas considerações é que duas lógicas distintas e oponentes têm se confrontado ao longo desse percurso, expressando as muitas disputas existentes no campo. 


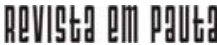

\} POLÍTICA DE ATENÇÃO - PRUDENCIO, J. D. L.; SENNA, M. C. M. \}

DOI: $10.12957 /$ REP.2022.63449

É possível destacar dois atores-chave como ferrenhos opositores à reforma orientada pela lógica antimanicomial. Um deles é representado pela Federação Nacional das Comunidades Terapêuticas (Febract), congregando um segmento heterogêneo e com práticas bem diversificadas entre si, mas movido por interesses de ordem religiosa e disputas em torno do fundo público (GUIMARÃES; ROSA, 2019). Outro ator fundamental diz respeito a uma parcela da categoria médica, liderada pela Associação Brasileira de Psiquiatria $(A B P)$, representando não apenas interesses corporativos, mas também da indústria farmacêutica e do complexo empresarial hospitalar (PEREIRA, 2020).

Esses opositores se fizeram presentes em todo o momento de implantação da reforma psiquiátrica brasileira, de diferentes maneiras e utilizando-se de estratégias as mais diversas para influenciar e vetar esse processo. Passos (2017) cita, por exemplo, que desde a institucionalização da Coordenação Nacional de Saúde Mental do Ministério da Saúde, ainda em 1991, esse espaço tem sido bastante disputado por esses atores, dado seu papel central na conformação da política de saúde mental. De acordo com Pereira (2020), até o ano de 2015, no entanto, estavam à frente dessa coordenação sujeitos defensores da reforma psiquiátrica antimanicomial, o que possibilitou, de forma inequívoca, os avanços na atenção às pessoas em sofrimento psíquico e usuários de álcool e outras drogas, bem como constituiu uma espécie de freio às tentativas de reversão das reformas implantadas.

Mas mesmo durante esse período, outras medidas em direção oposta aos princípios da reforma psiquiátrica antimanicomial foram adotadas e podem ser creditadas, em grande parte, à pressão desses grupos opositores, aliada a disputas internas na própria base governista. Aqui merecem destaque a instituição, por meio do Decreto n 7.179/2010, do Plano Integrado de Enfrentamento ao Crack, posteriormente transformado no Programa Crack, é possível vencer, e a Portaria n 131/2012 (BRASIL, 2012), que insere as comunidades terapêuticas na Raps como um dos componentes substitutivos.

Guimarães e Rosa (2019) argumentam que essas medidas partiram da narrativa, fortemente construída pela mídia, da existência de uma epidemia de crack, apesar de estudos epidemiológicos indicarem ser o álcool o principal problema de drogas no Brasil. As autoras assinalam que a partir daí abre-se uma disjuntiva entre a saúde mental e a questão do álcool e outras drogas, em meio a disputas por recursos públicos do orçamento do SUS. Em direção semelhante, Duarte (2018) sublinha que essa medida acaba por promover a aliança do governo com setores conservadores, dando ênfase às comunidades terapêuticas e abrindo espaço para a reedição da lógica proibicionista, criminalizante, higienista e manicomial contra a qual se pauta a reforma psiquiátrica brasileira. 


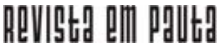

\} POLÍTICA DE ATENCC̃̃O - PRUDENCIO, J. D. L.; SENNA, M. C. M.

DOI: $10.12957 /$ REP.2022.63449

As comunidades terapêuticas ainda recebem reforço no período por meio da Portaria n. 131/2012 (BRASIL, 2012), que as reconhecem como serviço substitutivo no âmbito da Raps, aptas a receber recursos financeiros do SUS. No entanto, como advertem Guimarães e Rosa (2019, p. 121), essas instituições não se qualificam como serviço de saúde, haja vista sua forte vinculação à "perspectiva manicomial, com cunho religioso e sem equipe técnica para compor a rede". Cabe também mencionar a nomeação de Valencius Wurch para o cargo de coordenador nacional de saúde mental do Ministério da Saúde em 2015. Ex-diretor do então maior hospício privado da América Latina, frequentemente denunciado por maustratos e violação de direitos das pessoas em sofrimento psíquico, esse psiquiatra tem sua história profissional associada a práticas e interesses asilares, manicomiais e isolacionistas, o que gerou uma intensa mobilização de amplos setores dos movimentos em defesa da reforma psiquiátrica brasileira e culminou com sua saída do cargo em abril de 2016.

Se essas medidas, além de outras, já sinalizam para a reversão dos avanços conquistados pela reforma psiquiátrica antimanicomial, o contexto que se abre a partir do Golpe de 2016 aprofunda essa tendência em direção a um verdadeiro desmonte do processo construído ao longo de décadas, configurando o que Guimarães e Rosa (2019) denominam de remanicomialização do cuidado em saúde mental. No caso específico da atenção ao usuário de álcool e outras drogas, esse quadro é ainda acompanhado do reforço a práticas do proibicionismo à droga, que prega a abstinência total e o isolamento compulsório como únicos caminhos para lidar com o uso prejudicial do álcool e outras drogas.

Por meio de um conjunto de resoluções e portarias, com destaque para a Portaria n 3.588/2017 (BRASIL, 2017), que institui a chamada nova política de saúde mental, são introduzidas diversas alterações na orientação da política, em um claro movimento de contrarreforma. Dentre essas alterações encontram-se o aumento do financiamento para a internação psiquiátrica; o incentivo financeiro para ampliação de leitos psiquiátricos nos hospitais gerais; o desfinanciamento do modelo de atenção psicossocial de base comunitária; a ambulatorização do cuidado com equipes especializadas e a ampliação do aporte financeiro direcionado às comunidades terapêuticas (DUARTE, 2018; GUIMARÃES; ROSA, 2019; PEREIRA, 2020). Implica-se, assim, um reforço à tendência asilar com nítida priorização dos manicômios e das comunidades terapêuticas e esvaziamento do modelo de atenção psicossocial de base comunitária.

Cabe destacar que essas mudanças foram impostas sem uma ampla discussão com os setores e movimentos históricos da luta antimanicomial, interrompendo, desse modo, um legado de construção coletiva da política. Por outro lado, tais medidas foram amplamente apoiadas pela indústria farmacêutica, pelo empresariado médico-hospitalar, pela ABP e pela Federação Nacional das Comunidades Terapêuticas, dentre outras entidades 
(PEREIRA, 2020). Ademais, não se pode esquecer aqui do contexto de profunda austeridade fiscal imposta pela Emenda Constitucional n. 55/2016, que vem impondo cortes drásticos no conjunto de políticas sociais, dentre elas o próprio SUS.

O governo de Jair Bolsonaro, iniciado em janeiro de 2019, apresenta a tendência de maior aprofundamento das contrarreformas iniciadas nos anos anteriores. Em meio a uma agenda conservadora e ultraliberal, foi apresentada a Nota Técnica n. 11/2019 (BRASIL, 2019), que explicita a linha de atuação da política de saúde mental do governo federal por meio, dentre outras questões, da retomada da ampliação de leitos em hospitais psiquiátricos e do reforço às comunidades terapêuticas. Ao mesmo tempo, a condução da política nacional de álcool e drogas foi transferida do Ministério da Saúde para o Ministério da Cidadania, que tem se orientado pela lógica proibicionista e manicomial.

Essas medidas são ainda acompanhadas pelo esvaziamento das instâncias de participação e controle social, a exemplo do Conad, que, por meio do Decreto n. 9.926/2019, teve a participação de representantes da sociedade civil extinta, sob a alegação de acabar com o "viés ideológico" existente no conselho (PEREIRA, 2020). Por outro lado, a instauração, no Congresso Nacional, de uma Frente Parlamentar Mista em Defesa da Nova Política de Saúde Mental e da Assistência Hospitalar Psiquiátrica, no ano de 2018 (DUARTE, 2018), expressa bem a capacidade de rearranjo das forças conservadoras em direção ao retrocesso e desmonte da política de saúde mental, álcool e outras drogas e do próprio SUS.

O desmonte dos avanços construídos pela política de saúde mental, álcool e outras drogas na primeira década do século XXI é aprofundado no auge da pandemia por Covid-19 no país, com o reforço a ações repressivas no trato da questão e a condução de ações que legitimam a desresponsabilização do cuidado pelo Estado, reforçando o lugar da sociedade civil neste campo. Cabe atenção aqui à instituição, por meio da Portaria no 437/2020 (BRASIL, 2020), dos centros de referência em dependência química (Ceredeq), apresentados como espaço da sociedade civil aptos a serem um braço das universidades para o trabalho junto a "dependentes químicos" na realização da reinserção social, oferta de cuidado e estudos/pesquisa no campo da droga. Nota-se aqui que a própria expressão "dependentes químicos" demarca retrocessos na concepção dos usuários de álcool e outras drogas como sujeitos de direitos, além de fortalecer as comunidades terapêuticas conferindo-Ihes o estatuto de centros de referência a serem financiados com recursos públicos.

Seguindo essa tendência, em 2021 foi posto em votação na Assembleia Legislativa do estado do Rio de Janeiro o Projeto de Lei no 565/2019 (ALERJ, 2019), de autoria do deputado estadual e pastor Samuel Malafaia, irmão do pastor Silas Malafaia, defensor das comunidades terapêuticas. Esse PL apresenta as comunidades terapêuticas como política pública per- 


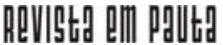

\} POLÍTICA DE ATENÇÃO - PRUDENCIO, J. D. L.; SENNA, M. C. M. \}

DOI: $10.12957 /$ REP.2022.63449

manente na atenção aos usuários de drogas, reforçando o olhar estigmatizante sobre os usuários de drogas associado à lógica da desobrigação estatal na garantia da atenção em saúde mental inscrita no SUS. Essas iniciativas representam, assim, o descaso público com a política de saúde mental e uma convocatória ao retrocesso pautado pela abstinência, pela "guerra às drogas" e pelo incentivo às comunidades terapêuticas no descarte do Caps-AD como espaço de suma importância na produção de cuidado em saúde mental.

Estudo realizado pelo Ipea (2021) sobre o orçamento federal destinado às políticas públicas sobre drogas no período de 2005 a 2019 demonstra bem as tendências aqui examinadas. Por meio de análise dos planos plurianuais (PPA) desse período, o Ipea traz importantes elementos para a reflexão acerca dos programas, ações e gastos públicos do governo federal com o tema droga no Brasil, ainda que com os limites expressos de não considerar os orçamentos dos entes subnacionais nem a alocação de recursos de ações relativas à intersetorialidade e/ou desdobramentos "em programas e ações de governo muito abrangentes" (IPEA, 2021, p. 7).

A análise realizada pelo Ipea considerou os gastos diretos e indiretos com a política sobre drogas elencados nos orçamentos dos seguintes setores: Ministério da Saúde; Ministério da Justiça e Segurança Pública; Presidência da República; Ministério da Cidadania; Ministério do Desenvolvimento Social; Ministério das Relações Exteriores; Ministério da Mulher, Família e Direitos Humanos; Secretaria de Direitos Humanos; Defensoria Pública da União; Ministério da Educação; órgãos da Segurança Pública; Anvisa; Ministério Público da União; Sistema Nacional de Atendimento Sócioeducativo; e Departamento Penitenciário Nacional. No presente artigo, foram abordados os gastos públicos destinados às políticas sobre drogas no âmbito do Ministério da Saúde e do Ministério da Justiça e Segurança Pública, responsáveis, ambos, pelas maiores iniciativas públicas nesse campo. São também esses os setores que protagonizaram as disputas em torno de concepções e práticas em relação ao tema nas últimas décadas.

Conforme apresentado anteriormente, o Ministério da Saúde assumiu um papel primordial na garantia e legitimação do cuidado em saúde dos usuários de álcool e outras drogas por meio dos Caps-AD, consultórios na rua e demais unidades de saúde, que compõem a Raps. Apesar disso, os gastos diretos com a política sobre drogas entre 2005 e 2012 - período em que se verificaram os maiores avanços na estruturação de uma rede de atenção de base extra-hospitalar pautada no reconhecimento dos usuários de álcool e outras drogas como sujeitos de direitos - ainda são majoritariamente dirigidos às práticas proibicionistas encampadas pelo Ministério da Justiça e Segurança Pública. Em 2005, os gastos diretos do Ministério da Saúde com a questão das drogas foram de R $\$ 37,5$ milhões, enquanto o Ministério da Justiça contou com o montante de R 143,8 milhões, aproximadamente quatro vezes mais do que o valor destinado ao Ministério da Saúde. 


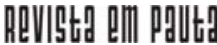

\} POLÍTICA DE ATENÇÃO - PRUDENCIO, J. D. L.; SENNA, M. C. M. \}

DOI: $10.12957 /$ REP.2022.63449

Ao final do período analisado pelo Ipea, houve uma significativa redução do volume total de gastos do Ministério da Saúde para a atenção aos usuários de álcool e outras drogas, correspondendo, em 2019, ao montante de R \$22,7 milhões, com valores corrigidos pelo IPCA-E. Já o total de gastos do Ministério da Justiça somava, no mesmo ano, o total de R \$ 421,2 milhões, o que corresponde a $88 \%$ do total de gastos diretos com políticas de drogas e quase 20 vezes mais do que as despesas diretas do $\mathrm{Mi}$ nistério da Saúde. Esses números demostram o descaso público com a implementação dos serviços de saúde mental no campo do álcool e outras drogas a partir dos princípios expressos na Lei no 10.216/2001 (BRASIL, 2001) e dos direcionamentos postos para o cuidado pela Paiuad, priorizando, assim, as ações de combate ao tráfico de drogas, a redução de demanda e oferta de drogas e o enfrentamento da criminalidade.

O estudo do Ipea discrimina as despesas efetuadas pelo Ministério da Saúde em cada ano por tipo de ação, o que permite relacioná-las às prioridades da gestão federal no campo do álcool e outras drogas ao longo do período. No período de 2005 a 2007, o Ministério da Saúde contou com um aporte de $R \$ 47,6$ milhões para a execução de serviços extra-hospitalares de atenção aos portadores de transtornos decorrentes do uso de álcool e outras drogas. Trata-se, como visto, do momento de implantação dos Caps-AD. Essas despesas, contudo, não tiveram continuidade nos anos seguintes.

No mesmo período, houve importante alocação de recursos para o auxílio-reabilitação psicossocial aos egressos de longas internações psiquiátricas, vinculado ao Programa de Volta para Casa, demonstrando o incentivo do governo federal para as ações voltadas à atenção aos usuários de drogas sob a perspectiva da reforma psiquiátrica antimanicomial. Os dados compilados pelo Ipea indicam que essa ação contou com aumento de recursos a cada ano, à exceção do período iniciado em 2015, a partir do qual o valor total do montante diminuiu. Aqui cabe considerar que, entre $2012 \mathrm{e}$ 2015, as despesas realizadas com essa ação incluíram a ênfase no enfrentamento da dependência de crack e outras drogas, indicando a prioridade ao programa Crack é possível vencer. No quadriênio seguinte, as despesas com essa ação passaram a contemplar objetivos mais abrangentes, voltados ao aprimoramento e implantação das redes de atenção à saúde, com ênfase na articulação das diversas redes temáticas, entre elas a Raps, mas com aporte menor de recursos.

Vale destacar que o período em que o Ministério da Saúde apresentou o maior volume de gastos diretos com políticas sobre drogas foi de 2013 a 2015, quando o valor salta de R\$ 36 milhões em 2011 para $R$ \$ 70,3 milhões em 2012, R \$ 753,8 milhões no ano seguinte e $R$ \$ 1,6 bilhões em 2014, com o maior valor em 2015, quando chega a $R \$ 1,7$ bilhões. Ressalta-se que, entre 2013 e 2017, os gastos diretos do Ministério da Saúde superaram os do Ministério da Justiça, e isso se deve a dois fatores principais. 


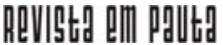

\} POLÍTICA DE ATENÇÃO - PRUDENCIO, J. D. L.; SENNA, M. C. M. \}

DOI: $10.12957 /$ REP.2022.63449

O primeiro é o investimento na Raps, com fortalecimento dos dispositivos que a compõem na busca pela atenção integral aos usuários de álcool e outras drogas com reconhecimento de seus direitos como cidadãos. A Portaria n. 3.088/2011 (BRASIL, 2011), que instituiu a Raps, altera a definição de rede de atenção em saúde mental e inaugura novas diretrizes orçamentárias para a política de saúde mental. Como afirma Duarte (2018), a Raps torna visível o que já se fazia no cuidado em saúde mental, mas mostra de forma engessada o processo de trabalho diante da escolha de alguns serviços para compor os pontos de atenção. Apesar disso, sem dúvidas houve um substancial incremento dos dispositivos extra-hospitalares implantados desde então.

O segundo aspecto é a ênfase dada ao enfrentamento do crack, por meio da prioridade conferida ao programa Crack é possível vencer. A noção difundida da existência de uma epidemia de crack, apesar das evidências científicas em contrário, e a adesão do governo federal à perspectiva de que era preciso combatê-la contribuíram para o aumento de recursos, ao mesmo tempo em que acirrava as tensões entre concepções divergentes sobre o tema no âmbito do próprio Ministério da Saúde.

O incentivo orçamentário a partir do programa de combate ao crack através do Crack é Possível Vencer chegou a acumular R \$ 84,9 milhões, conforme aponta a análise realizada pelo Ipea (2021). Tal valor representa o somatório de quatro anos, e só em 2017 a execução orçamentária para este programa atingiu 126,2\%, e, para a Raps, 112,8\%. Logo, cabe pontuar o aumento na cobertura em saúde mental no que tange a assistência extra-hospitalar, que ganhou força a partir do incentivo financeiro e fortaleceu o cuidado em saúde mental nos municípios com mais de 100\% de pagamento da dotação inicial.

Porém, a partir de 2017, como já apontado, há um aprofundamento, em escala acelerada, de intensos retrocessos na política de saúde mental, álcool e outras drogas. Esses retrocessos se tornam visíveis com a convocação de uma "nova política de saúde mental" e de uma nova Raps, por meio da Portaria no 3.588/2017 (BRASIL, 2017), que substitui a anterior, trazendo mudanças no que tange ao aumento do financiamento para as comunidades terapêuticas e à entrada dos hospitais psiquiátricos na Raps, apresentando um retorno à lógica manicomial e asilar de cunho abstêmio.

Essa virada na lógica do cuidado também pode ser visualizada por meio de mudanças significativas no orçamento público para os gastos diretos com a política sobre drogas no âmbito do Ministério da Saúde. É notório que entre 2017 e 2019 os recursos financeiros destinados a esta política sofrem uma severa mudança na composição orçamentária, passando de um total de $R \$ 1,6$ bilhões em 2017 para $R \$ 22,7$ milhões em 2019, cortes esses justificados ainda pelo regime de austeridade fiscal instituído com a EC n. 95/2016, contrastando com o aumento, no mesmo período, de R \$ 100 milhões por ano para o Ministério da Justiça e Segurança (IPEA, 2021). 


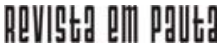

\} POLÍTICA DE ATENÇÃO - PRUDENCIO, J. D. L.; SENNA, M. C. M. \}

DOI: $10.12957 /$ REP.2022.63449

O que se verifica desde então é o revigoramento da declaração de "guerra às drogas" através de ações, pelo Ministério da Justiça e Segurança Pública, de combate à criminalidade e ao tráfico de drogas. A essa perspectiva se associam o sucateamento dos Caps-AD e a precarização nos contratos de trabalho dos trabalhadores da política de saúde mental (baixos salários, múltiplos empregos e não incorporação de novas práticas aos processos de trabalho), como bem apresenta Duarte (2018).

Essa situação demostra a importância da resistência dos trabalhadores da política de saúde mental para a garantia de uma política exercida pelos princípios da universalidade e intersetorialidade a partir da lógica territorial, em defesa da vida, com o protagonismo dos usuários e na luta constante pelo SUS. Mais do que nunca, é preciso resistir à lógica imposta pelo retorno a ações hospitalocêntricas e de enaltecimento da abstinência em oposição à estratégia de redução de danos.

\section{Considerações finais}

Diante da compreensão dos retrocessos concernentes à política de saúde mental, álcool e outras drogas no campo da saúde pública, os quais reforçam o traço da tendência repressiva nas ações destinadas aos usuários de drogas através da criminalização desses sujeitos, cabe salientar que a condução no trato desta política vem sofrendo fortes ataques na orientação do cuidado conduzido pela estratégia de redução de danos sociais e à saúde. A análise dos gastos dos dois principais ministérios, em termos de participação nos recursos públicos voltados a esse campo, demonstra a prevalência das ações no campo da repressão e declarações de guerra às drogas, ainda mais acentuada no período pós-2017.

Os dados mostram o irrisório orçamento destinado à política sobre drogas no âmbito do Ministério da Saúde, apesar de sua importância histórica na construção democrática e participativa, que permitiu a ampliação da atenção em saúde mental muito ancorada na militância e na construção do cuidado pelos trabalhadores desta política.

Apresentar os números possibilita maior compreensão da dimensão orçamentária destinada e também auxilia na compreensão do tamanho dos retrocessos esperados para o pós-2017. Isso porque, com a redução de mais de 1 bilhão para o Ministério da Saúde com o fim do programa Crack é Possível Vencer, o qual era a referência orçamentária neste campo até 2017, aliada ao novo trato do governo federal para com a agenda da política de saúde mental, álcool e outras drogas, declara-se uma era de retrocessos que afetaram diretamente ações de fomento e fortalecimento dos serviços extra-hospitalares, ampliação dos serviços para fortalecimento da atenção intersetorial ao usuários de drogas, expansão do auxílio reabilitação e alargamento da atenção em saúde mental de cunho psicossocial. 


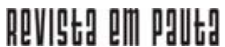

\} POLÍTICA DE ATENÇÃO - PRUDENCIO, J. D. L.; SENNA, M. C. M. \}

DOI: $10.12957 /$ REP.2022.63449

\section{Referências}

ALERJ. Projeto de Lei n. 565/2019. 2019. Disponível em: http:// alerjln1.alerj.rj.gov.br/scpro1923.nsf/0c5bf5cde95601f903256caa 0023131 b/b93a680c7fc3abdf832583f60069b88c?OpenDocument\& Highlight=0,565. Acesso em: 3 out. 2021.

AMARANTE, P. D. C. A. (Clínica) e a reforma psiquiátrica. In: AMARANTE, P. D. C. (Org.). Archivos de saúde mental e atenção psicossocial. Rio de Janeiro: Editora Nau, 2003.

BRASIL. Congresso Nacional. Lei Federal n. 10.216, de 6 de abril de 2001. Dispõe sobre a proteção e os direitos das pessoas portadoras de transtornos mentais e redireciona o modelo assistencial em saúde mental. Brasília, 2001. Disponível em: www.bvsms.saude.gov.br. Acesso em: 10 jun. 2021.

BRASIL. Ministério da Saúde. A política do Ministério da Saúde para a atenção integral a usuários de álcool e outras drogas. Brasília: Ministério da Saúde, 2003.

BRASIL. Ministério da Saúde. Portaria GM/MS n. 3.088, de 23 de dezembro de 2011. Institui a Rede de Atenção Psicossocial para pessoas com sofrimento ou transtorno mental e com necessidades de saúde decorrentes do uso de crack, álcool e outras drogas, no âmbito do Sistema Único Saúde. Brasília, 2011. Disponível em: www.saude.mg.gov.br. Acesso em: 10 jun. 2021.

BRASIL. Ministério da Saúde. Portaria n. 131, de 26 de janeiro de 2012. Institui auxílio financeiro às comunidades terapêuticas. Brasília, 2012. Disponível em: https://bvsms.saude.gov.br/bvs/saudelegis/gm/2012/ prt0131_26_01_2012.html. Acesso em: 3 out. 2021.

BRASIL. Ministério da Saúde. Portaria n. 3.588, de 21 de dezembro de 2017. Altera as Portarias de Consolidação n. 3 e n. 6, de 28 de setembro de 2017, para dispor sobre a Rede de Atenção Psicossocial, e dá outras providências. Brasília, 2017. Disponível em: http://bvsms.saude.gov.br/bvs/ saudelegis/gm/2017/prt3588_22_12_2017.html. Acesso em: 15 jun. 2021.

BRASIL. Ministério da Saúde. Nota Técnica n. 11. Esclarecimentos sobre as mudanças na política nacional de saúde mental e nas diretrizes da política nacional sobre drogas. Brasília, 2019. Disponível em: https://pbpd.org.br/ wp-content/uploads/2019/02/0656ad6e.pdf. Acesso em: 3 out. 2021.

BRASIL. Ministério da Cidadania. Portaria n. 437/2020, de 13 de julho de 2020. Estabelece parâmetros para o reconhecimento de organizações da sociedade civil como Centro de Referência em Dependência Química (Ceredeq). Brasília, 2020. Disponível em: https://www.in.gov.br/en/web/ dou/-/portaria-n-437-de-13-de-julho-de-2020-266876712 Acesso em: 18 jun. 2021. 


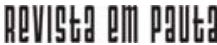

\} POLÍTICA DE ATENÇÃO - PRUDENCIO, J. D. L.; SENNA, M. C. M. \}

DOI: $10.12957 /$ REP.2022.63449

COE, N. M.; DUARTE, M. J. O. A construção da atenção psicossocial na política pública de saúde mental no Brasil: rupturas, tessituras e capturas. In: DUARTE, M. J. O.; PASSOS, R. G.; GOMES, T. M. S. Serviço Social, saúde mental e drogas. Rio de Janeiro: Papel Social, 2017.

COSTA, P. H. A.; RONZANI, T. M.; COLUGNATI, F. A. B. No meio do caminho tinha um Capsad: centralidade e lógica assistencial da rede de atenção aos usuários de drogas. Ciênc. saúde coletiva, Rio de Janeiro, v. 23, n. 10, out. 2018. Disponível em: https://www.scielo.br/j/csc/a/G3Vt dmgn3ymSRzB3zYqrqmR/abstract/?lang=pt\&format=htm. Acesso em: 3 out. 2021.

DUARTE, M. J. O. Política de saúde mental e drogas: desafios ao trabalho profissional em tempos de resistência. Revista Libertas, Juiz de Fora, v. 18, n. 2, jul./dez. 2018. Disponível em: https://periodicos.ufjf.br/index.php/ libertas/article/view/18604. Acesso em: 3 out. 2021.

GUIMARÃES, T. A. A.; ROSA, L. C. S. A remanicomialização do cuidado em saúde mental no Brasil no período de 2010-2019: análise de uma conjuntura antirreformista. O Social em Questão, ano XXII, n. 44, maio/ago. 2019. Disponível em: http://osocialemquestao.ser.puc-rio.br/media/osq_44_ art5.pdf. Acesso em: 3 out. 2021.

IPEA. Análise das políticas públicas sobre drogas no orçamento federal 2005 a 2019. Relatório Institucional. Brasília, 2021. Disponível em: https:/ /www.ipea.gov.br/portal/index.php?option=com_content $\&$ view $=$ a rticle\&id=37958\&ltemid=457. Acesso em: 10 jun. 2021.

LIMA, R. C. C. Uma história das drogas e do seu proibicionismo transnacional: relações Brasil Estados Unidos e os organismos internacionais. Tese (doutorado em Serviço Social) - Pós-Graduação em Serviço Social, UFRJ, Rio de Janeiro, 2009, mimeo.

LIMA, D. K. R. R.; GUIMARAES, J. E. Articulação da Rede de Atenção Psicossocial e continuidade do cuidado em território: problematizando possíveis relações. Physis, Rio de Janeiro, v. 29, n. 3, maio 2019. Disponível em: https://www.scielo.br/j/physis/a/46y3mHF9kdx7DHQGHwpspdf/ ?lang=pt. Acesso em: 3 out. 2021.

MACEDO, J. P. et al. A regionalização da saúde mental e os novos desafios da reforma psiquiátrica brasileira. Saúde e Sociedade, São Paulo, v. 26, n. 1, mar. 2017. Disponível em: https://pesquisa.bvsalud.org/portal/resource/ pt/biblio-962509. Acesso em: 3 out. 2021.

PASSOS, R. G. Luta antimanicomial no cenário contemporâneo: desafios atuais frente à reação conservadora. Sociedade em Debate, Pelotas, v. 23, n. 2, jul./dez. 2017. Disponível em: https://revistas.ucpel.edu.br/rsd/article/ view/1678. Acesso em: 3 out. 2021. 


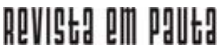

\} POLÍTICA DE ATENÇÃO - PRUDENCIO, J. D. L.; SENNA, M. C. M. \}

DOI: $10.12957 /$ REP.2022.63449

PEREIRA, S. L. B. A política de saúde mental brasileira em tempos neoliberais: projetos em disputa. Sociedade em Debate, Pelotas, v. 26, n. 1, jan./abr. 2020. Disponível em: https://revistas.ucpel.edu.br/rsd/article/view/2249. Acesso em: 3 out. 2021.

PITTA, A. M. F. Um balanço da reforma psiquiátrica brasileira: instituições, atores e políticas. Ciência e Saúde Coletiva, v. 16, n. 12, dez. 2011. Disponível em: https://www.scielo.br/j/csc/a/JnBHtt8Q8NNHFHbVw5ww5mC/ ?lang=pt. Acesso em: 3 out. 2021.

PRUDENCIO, J. D. L. A construção das redes de atenção aos usuários de álcool e outras drogas na saúde mental de municípios da Baixada Fluminense do estado do Rio de Janeiro. Tese (doutorado em Política Social) - Programa de Estudos Pós-Graduados em Política Social, UFF, Niterói, 2019.

DOI: $10.12957 /$ rep.2022.63449

Recebido em 24 de junho de 2021. Aprovado para publicação em 20 de setembro de 2021.

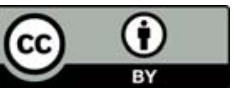

A Revista Em Pauta: Teoria Social e Realidade Contemporânea está licenciada com uma Licença Creative Commons Atribuição 4.0 Internacional. 